\title{
Study on Ecological Environment Monitoring in Mining Area based on Remote Sensing Information Extraction
}

\author{
Weiping Shi \\ College of Mining and Safety \\ Engineering \\ Shandong University of Science and \\ Technology \\ Qingdao, China \\ swp1128@163.com \\ Lei Yu \\ Shandong Electric Power Engineering \\ Consulting Institute Co., Ltd \\ Jinan, China \\ yulei@sdepci.com
}

\author{
Shengwen $\mathrm{Yu}$ \\ College of Mining and Safety \\ Engineering \\ Shandong University of Science and \\ Technology \\ Qingdao, China \\ skdkyswc@126.com
}

\author{
Hong $\mathrm{Hu}$ \\ Haihe River Water Conservancy \\ Commission Haihe River Basin water \\ and soil conservation monitoring center \\ Tianjin, China \\ 329314972@qq.com
}

\begin{abstract}
The large-scale exploitation and utilization of mineral resources not only brings great economic benefits to mankind, but also produce a series of geological disasters and environmental damages. Traditional monitoring methods require a large number of samples to be collected in the field and take a long time to obtain real-time information. In view of this, this paper puts forward a method to analyze the pollution of vegetation in mining area by using remote sensing image, so as to analyze the environmental damage in mining area timely and quickly. In this paper, spectrum and samples of vegetation was first collected in the field. The heavy metal content and chlorophyll content in the vegetation were tested, and the biological effects of heavy metal on plants were analyzed. Furthermore, the vegetation spectrum collected in the field is processed and analyzed. The vegetation spectral parameters are extracted. Then the model reflecting the spectral characteristics and the effects of heavy metals in vegetation is constructed by means of multivariate statistics. Finally, combined with the characteristics of remote sensing images, the destruction of vegetation in mining area is analyzed. The characteristics of remote sensing images are consistent with the processing results of spectral data collected on the ground. Therefore, it is indicated that remote sensing image can be used to monitor the destruction of ecological environment in mining areas.
\end{abstract}

Keywords-- ecological destruction of mining area, spectral characteristics, heavy metals, multiple regression analysis, image characteristics

\section{INTRODUCTION}

The large-scale exploitation and utilization of mineral resources not only brings great social and economic benefits to mankind, but also produce a series of geological disasters and environmental damages. In mining area, water, vegetation and soil are easy to be polluted by pit water, mineral processing wastewater and tailings. This pollution in mining area threats the survival environment of human and restricts the sustainable development of mines in our country. Traditionally, methods of geochemical data, hydrologic and water quality measurements or physical geographical data are used to analyze the pollution caused by harmful or even toxic elements in mining areas. These methods involve a large number of samples collecting in the field and a long time analyzing in laboratory. Besides, these methods can only obtain point information of the target, but not area information. Moreover, these methods could not get real-time information, which greatly limits the control speed of environmental pollution [1]. When vegetation invaded by pollutants and other unfavorable factors in growing process, spectral reflection from them will change. Therefore, remote sensing technology can be used to monitor and diagnose damages caused by ecosystem pollution on vegetation. Remote sensing biogeochemistry is a marginal discipline which combines biogeochemical theory and remote sensing theory. It is possible to study the biological effects of contaminated plants using the principles of remote sensing biogeochemistry [2]. Many plants are sensitive to geochemical environment in which they grow. They can accumulate most of the trace elements, which can represent the chemical conditions of soil, bedrock, groundwater and atmosphere in a large area around them. Thus it is possible to study the polluted status of mining areas based on remote sensing biogeochemistry.

Guyot and Beret [3] determined the position of red edge using four band reflectance. The location of the red edge is mainly related to the chlorophyll content of the leaf. The growth state of the vegetation can be monitored by the characteristics of red edge [4]. Blackburn proposed a simple ratio index of specific pigments (vegetation index) to estimate chlorophyll content [5]. Wolfgang et al. [6] extracted the red edge position of vegetation using derivative analysis technique of vegetation spectral curve and analyzed the vegetation pollution information caused by coal mining activities in mining area. Using hy perspectral data, $\mathrm{Pu}$ et al. [7] analyzed spectral curves of vegetation and estimated leaf area index of forest. 
Andreeva et al. [8] used hyperspectral remote sensing technology to analyze the pollution of vegetation under the influence of heavy metals. B.N.Rock, head of vegetation remote sensing research group of NASA Center, USA, used water effect index (1600-1630 nm/1230-1270 nm) to identify plant poisonings [9-10]. Liu et al. explored the correlation between spectral characteristics of rice, leaf area index and chlorophyll density by using hyperspectral data [11]. Taking rice and sugarcane as the research objects, Tian et al. studied the physiological and ecological characteristics and spectral characteristics of the poisoned plants [12]. Zhu et al. studied the physiological, ecological, spectral curves of plants and their remote sensing satellite image under the influence of oil and gas microleakage in Xinjiang [13]. Taking ficus microphylla as research objects, $\mathrm{Xu}$ studied characteristics of physiological, ecological, spectral curves and remote sensing images [14]. Dong et al. studied the physiological and spectral characteristics of sargassum by remote sensing biogeochemical method [15]. Gan used hyperspectral techniques to study the pollution status of mine [16-18]. Using hyperspectral technique, Zhao et al. estimated the biochemical parameters of surface vegetation [19]. Liu et al. studied the spectral characteristics of winter wheat under the influence of strip-induced diseases using multitemporal hyperspectral images [20].

Based on the principle of remote sensing biogeochemistry, taking No. 2 coal mine and No. 3 coal mine in Jining city as the study area, spectral data and environmental pollution information of vegetation are collected in this area. The spectrum of polluted plants was extracted by hyperspectral remote sensing. The multivariate model between spectrum and pollution status of vegetation is established. The destruction of vegetation in mining area is analyzed based on remote sensing images. By comparison between remote sensing images and spectral data collected in the field, the reliability of remote sensing image in environment monitoring in mining areas is verified in this paper.

\section{DATA ACQUISITION}

\section{A Overview of mining areas}

Jining city, located in Shandong province, is rich in mineral resources. In this city, the area in which coal is stored is about $4826 \mathrm{~km} 2$, accounting for $45 \%$ of the total area of the city. Jining mining area is one of the eight national key coal bases. In south of Jining city, No. 2 coal mine, No. 3 coal mine and small north lake area is an ideal experimental region. In this region, there are farmland, subsidence control areas, ground deformation relocation areas, and gangue mountains. Therefore, the experimental area is bounded by the Liangji Canal in the west, the G327 national highway - the old canal - the S342 provincial road in the north, the Sihe river in the east and the estuary of the

Sihe river in the south. Coordinates of this range is: N35'23'16.70', E116'32'30' (northwest), N35'14'8.44', E116 $45^{\prime} 4.42$ ', (southeast), as shown in Fig. 1. In summer and autumn, the main vegetation in Jining mining area is poplars, which are luxuriant and widely distributed. Thus poplars are used as the experimental vegetation to monitoring environmental pollution in mining area.

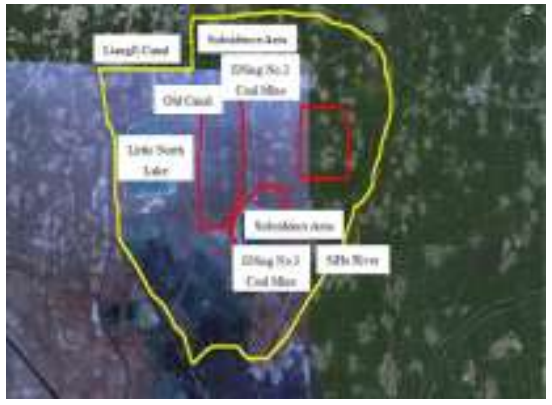

Fig.1. Image of mining area

\section{B Collection of spectrums and samples}

During spectrum sampling in the field, it is a complex process for the surface radiation energy reaching the sensor, which is affected by many factors. In order to determine the reflectivity of the ground object, two types of spectral radiation value need to be tested: The first type is the reference spectrum or the white standard plate, while the other is the spectrum of the object. The two spectrums need to be tested under the same lighting conditions. The reflectivity of the object is the spectrum of the target object divided by the reference spectrum [21]. The sampling interval from visible band to near infrared band is $1.4 \mathrm{~nm}$, and the sampling interval from other bands is $2 \mathrm{~nm}$ [22].

In the study area, poplars' spectral curves were tested. At each sampling point, ten spectral curves were collected and photographed. Several poplars were collected near the test points and mixed together, which can represent the mean characteristics of the vegetation in this sampling area, and reducing contingency error. The collected plant samples were mixed into a sample bag, and a label was attached outside of the sample bag to indicate the collection site and parts of plant. 3-5 leaves were selected and each leaf was tested 30-50 times. Several plant leaves were collected and placed in numbered water sample bags for later moisture test.

Physiological effects of poplar under the influence of six kinds of heavy metals $\mathrm{Cu}, \mathrm{Pb}, \mathrm{Cr}, \mathrm{Ni}, \mathrm{Mn}, \mathrm{Zn}$ were analyzed and studied in this paper. The contents of $\mathrm{Cu}, \mathrm{Pb}$, $\mathrm{Ni}, \mathrm{Cr}, \mathrm{Mn}$ and $\mathrm{Zn}$ were tested by combustion atomic absorption spectrometry in the laboratory.

\section{ANALYSIS ON HEAVY METAL EFFECT OF POPLAR IN MINING AREA}

The test results for the contents of various elements in poplars are shown in Table 1. The distributions of heavy metals and chlorophyll are shown in Fig. 2 and Fig. 3.

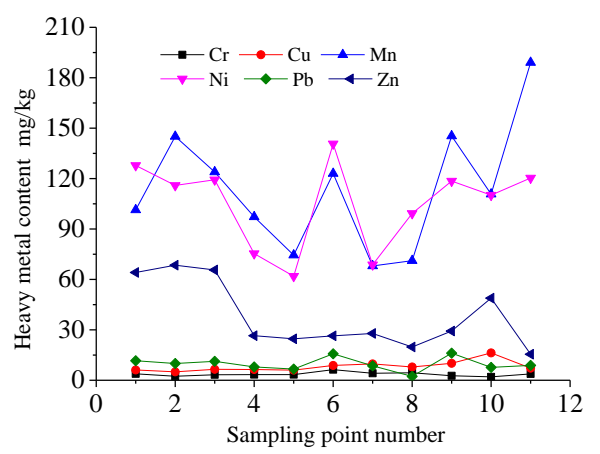

Fig.2. Heavy metal content of poplar 
TABLE1. Heavy metal content of poplar

\begin{tabular}{|c|c|c|c|c|c|c|c|}
\hline Points & $\mathbf{C r} /(\mathbf{m g} / \mathbf{k g})$ & $\mathbf{C u} / \mathbf{( m g} / \mathbf{k g})$ & $\mathbf{M n} / \mathbf{( m g} / \mathbf{k g})$ & $\mathbf{N i} /(\mathbf{m g} / \mathbf{k g})$ & $\mathbf{P b} /(\mathbf{m g} / \mathbf{k g})$ & $\mathbf{Z n} /(\mathbf{m g} / \mathbf{k g})$ & $\mathbf{C h l o r o p h y l l ~ / ( m g / g )}$ \\
\hline YS01 & 3.83 & 6.14 & 101.36 & 127.81 & 11.63 & 64.12 & 2.74 \\
\hline YS02 & 2.40 & 5.02 & 145.06 & 115.93 & 9.96 & 68.47 & 2.81 \\
\hline YS03 & 3.27 & 6.52 & 123.92 & 119.28 & 11.26 & 65.63 & 3.5 \\
\hline YS04 & 3.37 & 6.39 & 97.23 & 75.37 & 7.93 & 26.52 & 2.36 \\
\hline YS05 & 3.35 & 6.01 & 74.44 & 61.88 & 6.67 & 24.66 & 2.99 \\
\hline YS06 & 6.30 & 8.82 & 123.00 & 140.67 & 15.75 & 26.42 & 1.97 \\
\hline YS07 & 4.15 & 9.73 & 68.01 & 68.74 & 8.57 & 27.86 & 4.57 \\
\hline YS08 & 4.44 & 7.91 & 71.16 & 99.25 & 2.29 & 19.79 & 3.9 \\
\hline YS09 & 2.69 & 10.10 & 145.34 & 118.53 & 16.14 & 29.30 & 3.31 \\
\hline YS10 & 2.03 & 16.28 & 110.75 & 110.14 & 7.66 & 48.88 & 3 \\
\hline YS11 & 3.79 & 7.20 & 189.06 & 120.36 & 8.84 & 15.48 & 3.3 \\
\hline Normal value & $0.05-1$ & $1-17$ & $15-150$ & $1-3.4$ & $10-30$ & $20-50$ & \\
\hline
\end{tabular}



Fig.3. Chlorlphyll content of poplar

It can be seen that in this mining area the poplars polluted by $\mathrm{Ni}$ seriously. The content of $\mathrm{Ni}$ is in the range of $61.88-140.67 \mathrm{mg} / \mathrm{kg}$, which is much higher than the normal value $(1-3.4 \mathrm{mg} / \mathrm{kg})$. The content of $\mathrm{Cr}$ is in the range of $2.03-6.30 \mathrm{mg} / \mathrm{kg}$, which is higher than normal value $(0.05-1 \mathrm{mg} / \mathrm{kg})$. The content of $\mathrm{Cr}$ and $\mathrm{Ni}$ in YS06 point is much higher than the normal value, and much higher than other points. Therefore, YS06 point is seriously polluted by $\mathrm{Cr}$ and $\mathrm{Ni}$. The contents of $\mathrm{Cu}$ and $\mathrm{Mn}$ are almost in the normal range, except that the content of Mn in YS11 point is slightly higher than normal. The content of $\mathrm{Pb}$ is slightly lower than normal. The content of $\mathrm{Zn}$ is slightly higher than the normal value except YS01, YS02, YS03 points.

It can be seen that the chlorophyll content is in the range of $1.97-4.57 \mathrm{mg} / \mathrm{g}$. The highest content of chlorophyll in YS07 point is $4.57 \mathrm{mg} / \mathrm{g}$, and the lowest content of chlorophyll in YS06 point is $1.97 \mathrm{mg} / \mathrm{g}$. The content in other points is around $3 \mathrm{mg} / \mathrm{g}$. Due to the serious pollution of $\mathrm{Cr}$ and $\mathrm{Ni}$ in YS06 point, the growth of vegetation was damaged and the chlorophyll content was lower than normal vegetation.

\section{EXTRACTION AND ANALYSIS OF SPECTRUM}

\section{A Extraction method of spectral parameters}

In the process of vegetation growing, under the invaded by pollutants and other unfavorable factors, spectral reflection change, which is the basis for the use of remote sensing technology to diagnose and monitor the vegetation damage caused by ecosystem pollution. The main spectral parameters extracted in this paper are the depth of the red valley, the depth of water absorption valley, the red edge parameters, reflection intensity of green peak, the integral area of the water absorption valley, and all kinds of normalized indexes. In this paper, the height of green peak, the area of green peak, the depth of red valley, the area of red valley, the depth of water absorption valley and the area of water absorption valley are calculated using the local continuum normalization algorithm [21].

Red edge is the most obviously characteristic in plant spectral curve, which refers to the wavelength position corresponding to the maximum value of the first order differential spectrum between the 680-750 $\mathrm{nm}$. The location of the red edge is determined by the content of chlorophyll and phenological changes. The red edge parameters are generally calculated by the first derivative of the spectral reflectance in 680-750 nm wavelength region [23]. The red edge parameters mainly include the red edge position, the red edge peak value, the red edge slope, the area of red edge peak.

The red edge position shift refers to the movement of red edge in the direction of wavelength according to the change of chlorophyll content. The red edge displacement is closely related to the change of chlorophyll content in leaves. When the chlorophyll content declined, the red edge position generally shifts to the short wave direction, which is called blue shift. When the green plant grows with high chlorophyll content or the plants are deficient in water, the red edge position will shift to the long wave direction, which is called red shift [24].

Exponential characteristics are spectral waveforms and reflectance characteristics that quantitatively characterize physiological effects of plant canopy. That is to say, a certain mathematical model is used to describe the spectral waveform and reflectance characteristics of plant canopy. The two most widely used vegetation indices are the ratio vegetation index RVI and the normalized vegetation index NDVI [25], which can be used for monitoring of vegetation coverage and vegetation pollution.

$B \quad$ Analysis on spectrum of poplar

The poplar reflection spectrum is shown in Fig. 4. Poplar first-order differential (left) and second-order 
differential (right) spectra are shown in Fig. 5. The red edge parameters, green peak parameters, vegetation index, red valley parameters, and water absorption parameters are shown in Tables 2 and 3.

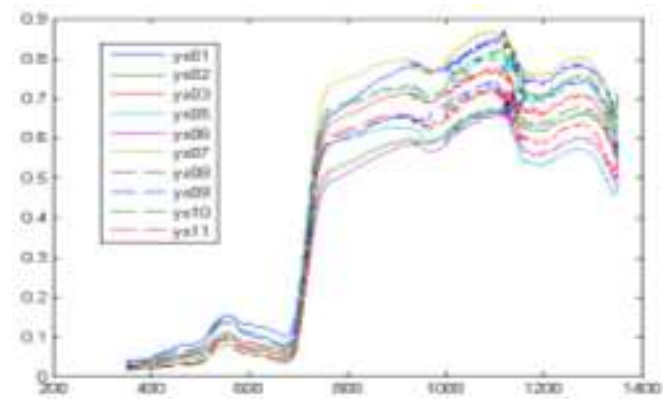

Fig.4. Reflectional spectrum of poplar

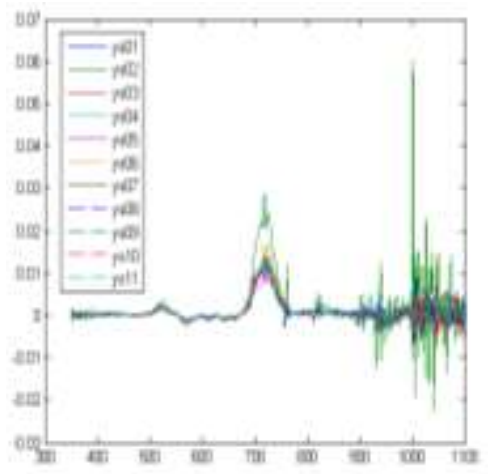

(a)

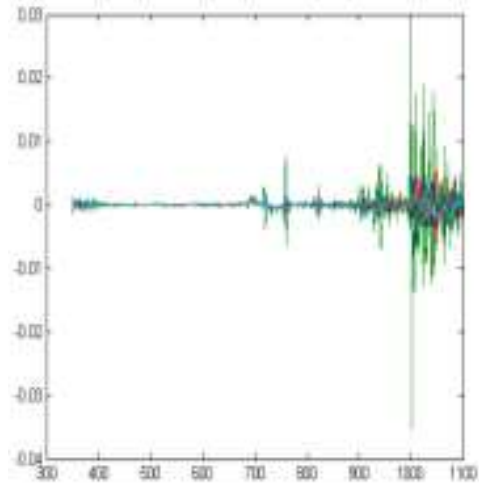

(b)

Fig.5. First-order detivate (a) and second-order derivate (b) of reflectional specrrum of poplar

It can be seen that near the $555 \mathrm{~nm}$ of leaves, a strong reflection peak-green peak is formed due to the effect of chlorophyll. Near $677 \mathrm{~nm}$, red absorption valleys are formed due to strong absorption of chlorophyll. In the vicinity of $960 \mathrm{~nm}$ and $1170 \mathrm{~nm}$, two water absorption valleys are formed due to water absorption. The red edge position is basically around $718 \mathrm{~nm}$ and basically no change in each point. The green-peak parameters and the red-valley parameters varied, with the green peaks in the range of $0.094-0.1552$, the area of green peaks in the range of 10.71119-23.4516, and the vegetation index in the range of 4.83-9.27.

TABLE2. The red edge parameters and green peak parametes of poplar and vegetation indices

\begin{tabular}{|c|c|c|c|c|c|c|c|c|}
\hline Points & $\begin{array}{c}\text { Red edge } \\
\text { position }\end{array}$ & $\begin{array}{c}\text { Red Edge } \\
\text { Peak }\end{array}$ & $\begin{array}{c}\text { Red edge } \\
\text { slope }\end{array}$ & $\begin{array}{c}\text { Red edge peak } \\
\text { area }\end{array}$ & $\begin{array}{c}\text { Green peak } \\
\text { position }\end{array}$ & $\begin{array}{c}\text { Green } \\
\text { peak }\end{array}$ & $\begin{array}{c}\text { Green peak } \\
\text { area }\end{array}$ & $\begin{array}{c}\text { Vegetation } \\
\text { index }\end{array}$ \\
\hline YS01 & 718 & 0.0116 & 0.0073 & 0.5195 & 557 & 0.1552 & 23.4516 & 4.4341 \\
\hline YS02 & 718 & 0.0125 & 0.0063 & 0.4462 & 555 & 0.0793 & 10.7119 & 7.3989 \\
\hline YS03 & 719 & 0.014 & 0.0077 & 0.5454 & 555 & 0.097 & 13.399 & 6.8434 \\
\hline YS04 & 718 & 0.0125 & 0.0072 & 0.5071 & 555 & 0.1115 & 15.0933 & 7.2974 \\
\hline YS05 & 718 & 0.0099 & 0.0056 & 0.3979 & 555 & 0.1057 & 15.6624 & 4.8246 \\
\hline YS06 & 724 & 0.0166 & 0.009 & 0.6351 & 555 & 0.1067 & 14.463 & 7.2456 \\
\hline YS07 & 718 & 0.014 & 0.0075 & 0.5336 & 554 & 0.094 & 10.9945 & 10.4149 \\
\hline YS08 & 719 & 0.0133 & 0.0068 & 0.4776 & 555 & 0.1363 & 19.4024 & 4.928 \\
\hline YS09 & 718 & 0.0137 & 0.0081 & 0.5743 & 556 & 0.1469 & 19.9689 & 6.7067 \\
\hline YS10 & 718 & 0.0133 & 0.0075 & 0.5312 & 555 & 0.0985 & 12.3543 & 9.2645 \\
\hline YS11 & 718 & 0.0146 & 0.0078 & 0.5544 & 555 & 0.1388 & 19.9018 & 5.7042 \\
\hline
\end{tabular}

TABLE3 The red valley parameters, water absorption parameters of poplar

\begin{tabular}{|c|c|c|c|c|c|c|c|c|c|}
\hline Points & $\begin{array}{c}\text { Red valley } \\
\text { position }\end{array}$ & $\begin{array}{c}\text { Red } \\
\text { valley } \\
\text { depth }\end{array}$ & $\begin{array}{c}\text { Red valley } \\
\text { area }\end{array}$ & $\begin{array}{c}\text { Position of } \\
\text { water } \\
\text { absorption 1 }\end{array}$ & $\begin{array}{c}\text { Depth of } \\
\text { water } \\
\text { absorption 1 }\end{array}$ & $\begin{array}{c}\text { Area } \\
\text { of water } \\
\text { absorption 1 }\end{array}$ & $\begin{array}{c}\text { Position } \\
\text { water } \\
\text { absorption 2 }\end{array}$ & $\begin{array}{c}\text { Depth of } \\
\text { water } \\
\text { absorption 2 }\end{array}$ & $\begin{array}{c}\text { Area of } \\
\text { Water } \\
\text { Absorption 2 }\end{array}$ \\
\hline YS01 & 678 & 0.7653 & 88.6073 & 971 & 0.0197 & 0.3833 & 1162 & 0.1031 & 7.2683 \\
\hline YS02 & 673 & 0.8541 & 107.416 & 961 & 0.0276 & 1.1345 & 1189 & 0.0637 & 4.078 \\
\hline YS03 & 677 & 0.8587 & 110.249 & 961 & 0.0293 & 1.1487 & 1147 & 0.1128 & 8.2773 \\
\hline YS04 & 677 & 0.8583 & 102.327 & 962 & 0.04 & 1.4346 & 1160 & 0.1488 & 10.7294 \\
\hline YS05 & 676 & 0.7893 & 94.3077 & 966 & 0.0284 & 1.0347 & 1177 & 0.115 & 8.0847 \\
\hline YS06 & 677 & 0.8666 & 112.717 & 965 & 0.0366 & 1.4711 & 1160 & 0.095 & 7.6881 \\
\hline YS07 & 676 & 0.9008 & 114.761 & 961 & 0.0342 & 1.345 & 1170 & 0.0937 & 7.2826 \\
\hline YS08 & 678 & 0.7865 & 93.7373 & 937 & 0.0372 & 1.4611 & 1130 & 0.1013 & 6.5981 \\
\hline YS09 & 676 & 0.8385 & 96.5584 & 961 & 0.0303 & 1.1051 & 1160 & 0.1161 & 7.9496 \\
\hline YS10 & 677 & 0.8928 & 111.728 & 965 & 0.0453 & 1.7074 & 1151 & 0.1324 & 10.4763 \\
\hline YS11 & 677 & 0.8218 & 96.8835 & 965 & 0.0423 & 1.7753 & 1162 & 0.1063 & 8.2889 \\
\hline
\end{tabular}




\section{REGRESSION ANALYSIS BETWEEN HEAVY METAL AND SPECTRAL PARAMETERS OF POPLAR}

In order to estimate the content of heavy metal from the spectrum, this section establishes a multivariate model [21, 26, 27]. Multiple linear regression model is usually expressed as:

$$
y=b_{0}+b_{1} x_{i 1}+b_{2} x_{i 2}+\cdots+b_{n} x_{i n}, i=1,2, \cdots, n
$$

where $y$ is the underestimate measurement, and $x$ is a variety of related factors. In this study, $y$ is the content of heavy metal; $x$ is the spectral parameters; $b$ is the linear regression coefficient and constant.

In this paper, the stepwise regression method is used to establish the multivariate linear regression model, and the stepwisefito function in Matlab is used to realize its calculation and its related parameter test. The upper limit of risk probability is set to $0.10-0.20$ when the spectral parameters are pre-selected into the regression model, and the lower limit of risk probability is set to 0.20 for pre-elimination. The contents of heavy metals and chlorophyll in poplar leaves in mining area were analyzed by multiple regression analysis using 12 kinds of spectral parameters. 11 samples were used and 9 samples were taken as regression model samples. The other two were used as samples to test the reliability of the model. Regression results are shown in Table 4. Reliability analysis on regression equations are shown in Table 5.

According to the analysis, the correlation between $\mathrm{Cr}$ content and red edge peak in poplar was relatively high, as the correlation coefficient of regression equation was $62 \%$, and the average deviation was $51 \%$, so the estimated accuracy was not high. The correlation between $\mathrm{Cu}$ content and red edge peak area was relatively high, as the correlation coefficient of the regression equation was $65 \%$, and the average deviation was $33 \%$, so the estimated accuracy was high. The correlation between $\mathrm{Ni}$ content and three parameters of red edge slope, vegetation index, area of water absorption 2 was relatively high, as the correlation coefficient of the regression equation was as high as $93 \%$, and the average deviation was $23 \%$, so the estimated accuracy was high. The correlations between $\mathrm{Pb}$ content and red edge peak area, depth of water absorption 1 was relatively high, as the correlation coefficient of the regression equation was $85 \%$, and the average deviation was $2 \%$, so the estimation accuracy was very high. The correlation between the $\mathrm{Zn}$ content and the depth of water absorption 1 was relatively high, as the correlation coefficient of the regression equation was $72 \%$, and the average deviation was $49 \%$, so the estimated accuracy was not high. The correlations between chlorophyll content and three parameters of red edge peak, green peak area and vegetation index was relatively high, as the correlation coefficient of the regression equation was $97 \%$, and the average deviation was $25 \%$, so the estimated accuracy was high.

TABLE4 Regression results of elements contents and spectral parameters in poplar

\begin{tabular}{|c|c|c|c|c|c|}
\hline Elements & Spectral parameters & $\begin{array}{c}\text { Spectral parameter } \\
\text { symbols }\end{array}$ & Regression equations & $\begin{array}{c}\text { Uncorrelated } \\
\text { significance probability }\end{array}$ & $\begin{array}{c}\text { Multiple } \\
\text { correlation } \\
\text { coefficient }\end{array}$ \\
\hline $\mathrm{Cr}$ & Red edge peak & $x_{1}$ & $\mathrm{Cr}=383.43 * x_{1}-1.28$ & 0.08 & 0.62 \\
\hline $\mathrm{Cu}$ & Red edge peak area & $x_{3}$ & $\mathrm{Cu}=16.8 * x_{3}-1.25$ & 0.06 & 0.65 \\
\hline \multirow{3}{*}{$\mathrm{Ni}$} & Red edge slope & $x_{2}$ & \multirow{3}{*}{$\begin{array}{c}\mathrm{Ni}=26800 * x_{2}-8.21 * \\
\mathrm{x} 6-9.09 * x_{12}+31.41\end{array}$} & 0.003 & \multirow{3}{*}{0.93} \\
\hline & Vegetation index & $x_{6}$ & & 0.03 & \\
\hline & Area of water absorption 2 & $x_{12}$ & & 0.02 & \\
\hline \multirow{2}{*}{$\mathrm{Pb}$} & Red edge peak area & $x_{3}$ & \multirow{2}{*}{$\mathrm{Pb}=-6.75+51.90 * x_{3}-316.68 * x_{9}$} & 0.01 & \multirow{2}{*}{0.85} \\
\hline & Depth of water absorption 1 & $x_{9}$ & & 0.09 & \\
\hline $\mathrm{Zn}$ & Water absorption depth & $x_{9}$ & $\mathrm{Zn}=-2346.4 * x_{9}+113.06$ & 0.03 & 0.72 \\
\hline \multirow{3}{*}{ Chlorophyll } & Red edge peak & $x_{1}$ & \multirow{3}{*}{$\begin{array}{c}\text { Yls }=447.09 * x_{1}-0.09 * \\
x_{5}-0.54 * x_{6}+2.25\end{array}$} & 0.0005 & \multirow{3}{*}{0.97} \\
\hline & Green peak area & $x_{5}$ & & 0.04 & \\
\hline & Vegetation index & $x_{6}$ & & 0.001 & \\
\hline
\end{tabular}

TABLE5 Reliability analysis on regression equations

\begin{tabular}{|c|c|c|c|c|c|}
\hline Regression equations & Ponits & Measured data & Estimated value & Relative deviation & Mean deviation \\
\hline \multirow{2}{*}{$\mathrm{Cr}=383.43 * x_{1}-1.28$} & YS10 & 2.03 & 3.82 & $88 \%$ & \multirow{2}{*}{$51 \%$} \\
\hline & YS11 & 3.79 & 4.32 & $14 \%$ & \\
\hline \multirow{2}{*}{$\mathrm{Cu}=16.8 * x_{3}-1.25$} & YS10 & 16.28 & 7.67 & $53 \%$ & \multirow{2}{*}{$33 \%$} \\
\hline & YS11 & 7.2 & 8.06 & $12 \%$ & \\
\hline \multirow{2}{*}{$\begin{array}{c}\mathrm{Ni}=26800 * x_{2}-8.21 * \\
\mathrm{x} 6-9.09 * x_{12}+31.41\end{array}$} & YS10 & 110.14 & 61.19 & $44 \%$ & \multirow{2}{*}{$23 \%$} \\
\hline & YS11 & 120.36 & 118.33 & $2 \%$ & \\
\hline \multirow{2}{*}{$\mathrm{Pb}=-6.75+51.90 * x_{3}-316.68 * x_{9}$} & YS10 & 7.66 & 6.48 & $2 \%$ & \multirow{2}{*}{$2 \%$} \\
\hline & YS11 & 8.84 & 8.63 & $2 \%$ & \\
\hline \multirow{2}{*}{$\mathrm{Zn}=-2346.4 * x_{9}+113.06$} & YS10 & 48.88 & 6.76 & $86 \%$ & \multirow{2}{*}{$49 \%$} \\
\hline & YS11 & 15.48 & 13.8 & $11 \%$ & \\
\hline \multirow{2}{*}{ Yls $=447.09 * x_{1}-0.09 * x_{5}-0.54 * x_{6}+2.25$} & YS10 & 3 & 2.12 & $29 \%$ & \multirow{2}{*}{$25 \%$} \\
\hline & YS11 & 3.3 & 3.96 & $20 \%$ & \\
\hline
\end{tabular}




\section{EXTRACTION AND ANALYSIS ON REMOTE SENSING IMAGES OF MINING AREA}

The image in this paper is from HJ-1A hyperspectral satellite. The HJ-1A satellite is equipped with a hyperspectral imager. The hyperspectral imager has 115 working spectral bands. The spectral range is $0.459-0.956$ $\mu \mathrm{m}$, and the average spectral resolution was $4.32 \mathrm{~nm}$.

A Vegetation index

Normalized vegetation index

$$
N D V I=(N I R-R) /(N I R+R)
$$

Ratio vegetation index

$$
R V I=N I R / R \text {. }
$$

Between them, NIR is the band near infrared and $R$ is the red band.

$$
-1<=N D V I<=1 \text {. }
$$

Negative values indicate that the ground is covered by clouds, water, snow, etc., which has high reflectance to visible light. 0 value indicates that there is rock or bare soil, so NIR and Rare approximately equal. Positive value indicates that there is covered by vegetation, and the positive value increases as the increasing of coverage [28]. In image, the band near infrared is $795 \mathrm{~nm}$ and the red band is $652 \mathrm{~nm}$. The normalized vegetation index (NDVI) is shown in Fig. 6. In the picture, cyan area represents non-vegetated areas, such as water, mining areas and bare land. Yellow area represents areas with relatively small vegetation coverage, such as paddy fields, uncultivated land, uncontaminated coal gangue, and subsidence areas. Red area was the area where the vegetation coverage is large. The normalized vegetation index near the mining area was low, indicating that the vegetation was damaged.

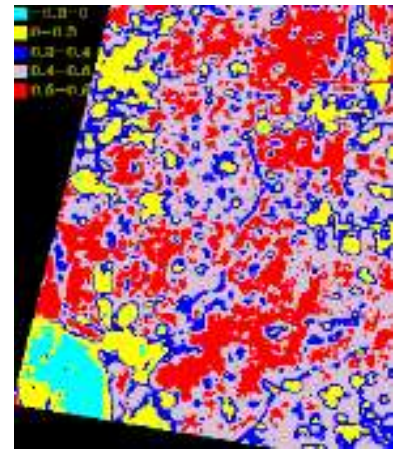

Fig.6. The map of normalized vegetation index of HJ-1A image

The band near infrared of image for RVI is $727 \mathrm{~nm}$ and the red band is $678 \mathrm{~nm}$. The ratio vegetation index is shown in Fig. 7. It can be seen that, compared with the spectral data collected in the field, the ratio of near-infrared and red bands of the vegetation is relatively small, which is generally less than 2; while the ratio of the ground spectral data is generally greater than 2 , always with the average value 7 . The vegetation near the mining area is contaminated, thus the reflectance in the near-infrared band declined. The red band weakens due to absorption of chlorophyll, and the reflectance becomes larger. Therefore, the resulting ratio vegetation index is smaller than that far away from the contaminated area. In comprehensive analysis, when the vegetation is contaminated, the normalized vegetation index and ratio vegetation index are smaller than those of normal vegetation.

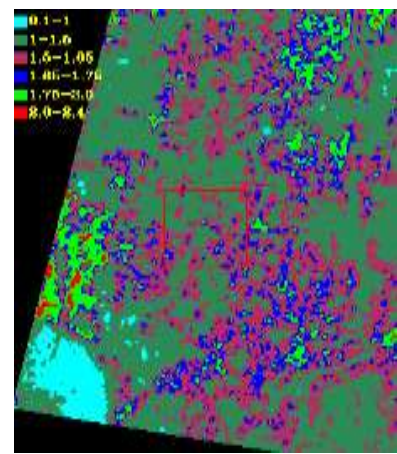

Fig.7. The map of ratio vegetation index of HJ-1A image

$B \quad$ Position of red edge and depth of red valley Formula for red edge position is:

$$
\mathrm{REP}=700+40 *\left[\frac{\mathrm{R}_{\text {rededge }}-R_{700}}{R_{740}-R_{700}}\right]
$$

where $R E P$ is the red edge position, and Rrededge $=(R 670$ - $R 780) / 2$ is the red edge reflectivity. R670, R700, R740, and R780 correspond to the $71,85,77$, and 92 bands of the image, respectively.

The red edge position is shown in Fig. 8. It can be seen that most of the red edge positions of the vegetation are overestimated, which may be related to the selected method. However, by comparison, the position of the red edge of the vegetation near the mining area is blue-shifted with respect to the position of the red edge of the vegetation far from the mining area, and the red edge moves toward the short-wave direction.

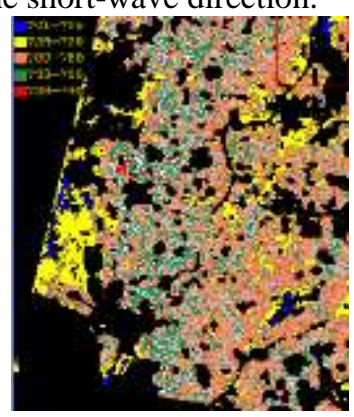

Fig.8. The map of vegetation red edge position

The red valley depth [29] is:

$$
D=1-R^{\prime}
$$

where $R^{\prime}$ is the reflectance value after the envelope is removed.

In this paper, the wavelength of the red band is $683 \mathrm{~nm}$, which is the $73 \mathrm{rd}$ band of the image. The depth of the red valley is shown in Fig. 9. It can be seen that the depth of the red valley near the mining area is relatively shallow, which is because the vegetation near the mining area is polluted. Thus the chlorophyll content is declined, and the absorption of the red band is weakened. Therefore the red valley becomes shallow.

The above NDVI, RVI, red edge position, and red valley depth all reflect the growth status of the vegetation. When the vegetation grows well and the vegetation coverage is high, the NDVI and RVI values are high. And the red edge position is generally around $720 \mathrm{~nm}$, as well as the red valley depth is generally around 0.6. When the vegetation is contaminated, the NDVI and RVI values are low. And the red edge position is generally blue-shifted 
(moves in the short-wave direction), as well as the depth of red valley becomes shallower. This is consistent with the results of the spectral data collected on the ground. Therefore, remote sensing image can be used to monitor the ecological environment damage in mining areas.



Fig.9. The map of red valley depth

\section{CONCLUSIONS}

In view of limitations of traditional pollution monitoring methods in coal mining areas, such as long time consumption, limited sampling range, and large workload of experimental analysis, this paper proposes the method of remote sensing image features to analyze the status of vegetation pollution in mining areas. Taking the Jining mining area as an example, the content of heavy metals in poplars in the mining area was obtained. The spectral parameters of poplar were extracted, and the correlation between heavy metal content, chlorophyll content and spectral parameters was established by means of vegetation biochemical analysis and spectral characteristic analysis. And the multivariate model of biochemical substances in plants was established. The NDVI, RVI, red edge position, and the depth of red valley of the vegetation were extracted from remote sensing images. Comparing images of vegetation in mining area with images of normal vegetation, it is shown that when the vegetation is polluted by heavy metals, the NDVI and RVI values are generally smaller than those of the normal vegetation, and the red edge position generally occur blue shift and the depth of the red valley becomes shallow. This is consistent with the processing results of the spectral data collected on the ground. Therefore, remote sensing image can be used to monitor the ecological environment damage in mining areas.

\section{ACKNOWLEDGEMENT}

This study was supported by the National Natural Science Foundation of China [grant numbers [51604164].

\section{REFERENCES}

[1] You Xianxiang, and et al. Theory of remote sensing and its application in resources and environment, Beijing: China Forestry Publishing House, 2003.

[2] Xu Ruisong, Ma Yueliang, and He Zaicheng, Remote sensing biogeochemistry, Guangdong: Guangdong publishing house of science and technology, 2003,

[3] Clevers J G P W. Imaging spectrometry in agriculture-plant vitality and yield indicators, Hill J, Megier J. Imaging spectrometry a tool for environmental observations, Dordrecht:Kluwer Academic, 1994.

[4] Demetriades Shahth, Steven MD, and Clark J A. "High resolution derivative spectra in remote sening," Remote Sensing, vol. 11, no. 10, pp. 1755-1773, 1990.

[5] Blackburn G A, "Quantifying chlorophylls and caroteniods at leaf and canopy scales: an evaluation of some hyperspectral approaches," Remotesens Enviroment, vol. 66, pp. 273-285, 1998.

[6] Lu Xia, Liu Shaofeng, and Zheng Liquan, "High spectral resolution data applied to identify plant stress response to heavy metal in in mining site," Science of Surveying and Mapping, vol. 32, no. 4, pp. 79-83, 2007.

[7] Jordan C F. "Derivation of leaf area index from quality of light on the forest floor," Ecology, vol. 50, pp. 663-666, 1969.

[8] Curran PJ. "Remote sensing of foliar chemistry," Remote sensing of Environment, vol. 30, pp. 271-278, 1990.

[9] Ustin S L, Roberts D A, Gardner M, and et al. "Evaluation of the potential of hyperion data to estimate wildfire hazard in the front range, California," Proceeding of IGARSS02, pp. 24-28, 2002.

[10] Guan Y, Guo S, Liu J, and Zhang X, "Algorithms for the estimation of the concentration of the chlorophyll a and carotenoids in rice leaves from airborne hyperspectral data," Computational Science-ICCS: 5th International Conference Atlanta, GA, USA, pp. 22-25, Proceeding, part I, 2005.

[11] Liu Weidong, Xiang Yueqin, Zheng Lanfen and et al. "Relationships between Rice LAI, CH. D and Hyperspectra Data," Journal of Remote Sensing, vol. 4, pp. 279-283, 2004.

[12] Guo Shizhong, Tian Guoliang, and Wang Shuihua, "Effects of sulfur dioxide and heavy metals such as cadmium and copper on spectral characteristics of plants," Environmental Science, vol.6, pp. 230-245, 2004.

[13] Yang Bailin, Zhu Zhenghai, and Li Jiancheng, "The mehanism governing fims remote sensing image tones of a certain oil-gas area in the junggar basin, xinjiang," Geochemistry, vol. 3, pp. 110-116, 1991.

[14] Xu Ruisong, and Yan Liying, "Study on the reflectance spectra of leaflets in Guangzhou City," Remote Sensing Information, vol. 2, pp. 124-135.

[15] Dong Yuguo, Li Tiefang, and et al. Investigation report on quantitative distribution of algae (mainly sargassum) from TM satellite remote sensing images in Daya Bay, Research report of Guangdong Nuclear Power Joint Venture Company, 1998.

[16] Gan Fuping, Wang Runsheng, and Ma Ainai, "Spectral ident ificat ion tree (sit) for mineral extract ion based on spectral characterist ics of minerals," Geoscience Frontiers, vol. 10, no. 2, pp. 446-450, 2003,.

[17] Gan Fuping, Wang Runsheng, Guo Xiaofang, and et al. "Extraction for rock and ore deposits information and prospects for application of geology," Remote Sensing for Land \& Resources, vol. 3, pp. 38-41, 2000.

[18] Gan Fuping,Liu Shengwei, and Zhou Qiang, "Identif ication of mining pollution using hyperion data at dexing copper mine in Jiangxi province , China," Earth Science, vol. 29, no. 1, pp. 119-126, 2004.

[19] Zhao Dehua, Li Jianlong, and Song Zijian, "Hyperspectral remote sensing for estimating biochemical variables of canopy," Advances in Earth Science, vol. 18, no. 1, pp. 119-126, 2003.

[20] Liu Liangyun, Huang Muyi, Huang Wenjiang, and et al. "Monitoring stripe rust disease of winter wheat using multi-temporal hyperspectral airborne Data," Journal of Remote Sensing, vol. 8, no. 1, pp. 59-64, 2004.

[21] Zhou Guangzhu, Study of plants spectrum features and infomation extraction in dexing copper mining area, Qingdao: Shandong University of Science and Technology, 2007.

[22] Li Qingting, The extration and analysis of remote sensing biogeochemistry effects of vegetation in de-ring copper mine area, Qingdao: Shandong University of Science and Technology, 2006.

[23] Wang Xiaoke, and Bai Yanying, "Application and development of terrestrial biogeochemical model," Chinese Journal of Applied Ecology, vol. 13, no. 12, pp. 1703-1706, 2002.

[24] Li Na, The spectral and image characteristic's of vegetation in the press of heavy metal, Qingdao: Shandong University of Science and Technology, 2007.

[25] Li Xiaowen, and Wang Jindi, Vegetation optical remote sensing model and parameterization of vegetation structure, Beijing: Science Press, 1995.

[26] Tong Qingxi, Zhang Bing, and Zheng Lanfen, Multispectral applications of hyperspectral remote sensing, Beijing: Publishing House of Electronics Industry, 2006, The First edition. 
[27] Yan Yanlu, Zhao Longlian, Han Donghai, and et al. Fundamentals and applications of near infrared spectroscopy, Beijing: China Light Industry Press, 2005.

[28] Zhao Yingshi, Remote sensing application analysis principles and methods, Beijing, Science Press, 2006.
[29] Liu Shengwei, Gan Fuping, and Wang Runsheng, The application of hyperion data to extracting contamination information of vegetation in the dexing copper mine, Jiangxi province, China," Remote Sensing for Land \& Resources, vol. 59, no. 1, pp. 19-26, 2004. 